\title{
The introduction of digital technologies in the educational process of training lawyers
}

\author{
Svetlana Mironova $^{1 *}$, Tamara Bogdanova ${ }^{1}$, and Svetlana Simonova ${ }^{1}$ \\ ${ }^{1}$ Volgograd Institute of Management, branch of the Russian Presidential Academy of National Economy and Public \\ Administration, 400040, Volgograd, Russia
}

\begin{abstract}
The article is devoted to the problems of introducing digital technologies in the educational process of training lawyers. The authors' team examines the history of the development of LegalTech in the Russian Federation and abroad, examines questions about the use of information technology in the training of lawyers, the requirements for modern lawyers and what skills they should possess, the requirements for modern teachers and teaching methods. The article reviews the university programs of higher education, as well as additional education (advanced training), aimed at studying digital technologies, and also examines information products aimed at improving the quality of work of lawyers offered by other organizations. The problems of digitalization of education and the introduction of information technologies in the educational process are identified and ways of their solution are outlined. The results of the study are practically relevant for the government, universities and educational centers, engaged in improving the education of lawyers.
\end{abstract}

\section{Introduction}

Recently, in Russia in connection with the implementation of the national program "The Digital Economy of the Russian Federation", there have been issues related to the digital transformation of legal education, which implies the process of transferring the current state of lawyers training to a new educational platform that takes into account the digitization of society and the economy.

The transition to the latest digital technologies in jurisprudence does not imply a purely online format for the work of lawyers. The digital age is the era of verbal communication. That is, the ability to present their expert opinion in an understandable and accessible way becomes popular in the labor market. This increases the speed of decision making. The speed and resources of search, selection and analysis of information also change, which requires a new generation of lawyers to be able to analyze large data arrays and build them into logical structures. Thus, modern lawyers should skillfully combine both traditional and innovative aspects of the profession.

The digitization of the economy, according to experts, can lead to the fact that a significant part of the work of lawyers will be successfully performed by robots. Increasingly, the legal community and teachers are asking the question: what should be the legal education of the future in order to allow professionals to remain in demand?
Modern digital technologies provide new tools for the development of universities and other educational institutions around the world. Digitalization provides opportunities for sharing lessons learned and knowledge. Electronic Learning (e-Learning), that is, a system for training trainees, using digital technologies, information resources and Internet space, is becoming increasingly widespread. For higher education institutions training future lawyers, the introduction of digital technology is extremely important in connection with the transition to a digital economy. In the transition to information technology of training of future lawyers in the wake of the digital economy, it is important to ensure the interaction of the various components of the educational process so that they become more dynamic, flexible and adaptive.

\section{Materials and methods}

Systemic analysis is the main method, employed during this study. It allows regarding the main activities of Russian universities, as well as other educational centers in terms of the use of digital technologies and the development of educational programs aimed at obtaining LegalTech skills by future and existing lawyers.

The data sample includes information, hosted on official web-sites of the Russian universities, educational centers, as well as government bodies of the Russian Federation.

* Corresponding author: smironova2017@gmail.com 


\section{Results}

The study resulted in the following conclusions. The development of information technologies in the world as a whole, including in the legal sphere, predetermines the need to change the approaches to training lawyers. The improvement of educational technologies should go in three directions: 1) the introduction of new information technologies into the educational process at the university, which will help future lawyers to get those competencies that will be useful to them in the profession. At the same time, such introduction should concern the application of technologies already within the framework of existing disciplines. For example, these are the introduction of online courses, the use of special programs, etc., and the introduction of new courses into the educational process aimed at studying new legal relations arising with the introduction of information technologies. The second is training in information technologies and legal relations with their use of already existing lawyers in the framework of advanced training, which will allow them to improve their professional skills. Third, the training of teachers themselves assumes new technologies that they can implement in the learning process.

\section{Discussion}

The development implies the use of information technology in training lawyers.

Various sources have different interpretations of the interdisciplinary term "monitoring".

Over the past 30 years, the work of a lawyer has changed a lot, has become more automated. Thus, according to experts, no more than $30 \%$ of legal activity is replaced technologies. Besides, from 4 to $5 \%$ is the share of available legal online services $[1,2]$.

The appearance in 1990 of Microsoft Office greatly facilitates the work of lawyers, now all documents can be prepared in a printed form, correct errors before the document is printed, save sample documents.

The first reference legal systems (RLS) appeared in the 60 s of the last century in Belgium and the USA (CREDOC and Lexis). ATP "Lexis" is actively used, not only in the United States, but also in the United Kingdom and Australia. Its reference legal systems exist in all developed countries.

In 1975, the USSR also has its own system, Etalon, which was used in state structures. In 1989 a commercial database "Legal Reference and Information System" appeared.

In 1990, the reference and legal service "Garant" appeared, and two years later - the RLS "Consultant Plus". These legal systems can significantly reduce the time to search for information.

Further, the emergence of new legal systems is increasing, among them: the RLS "Code", the RLS "Lawyer", the RLS "Zakon", "LexPro" and others. Despite the large number of reference and legal systems, students are traditionally taught in universities to work with RLS "Garant", RLS "Consultant Plus". These systems are not inferior to foreign. In addition to the RLS described above, there is also a high-tech e-justice system in Russia - KAD.ARBITR, which was originally created in arbitration courts, and today a similar system is being actively implemented in courts of general jurisdiction.

In the past few years, other legal technologies have become popular, which allow forming a complaint, statement, etc. in a relatively short time. An example is: Autolawyer (constructs complaints to the insurance company for an incorrectly determined bonus-malus coefficient for OSAGO); Jeffit (drawing up projects, reports, time tracking, registration of cases, integration with KAD.ARBITR); Flexbby (automates workflow, procurement and tenders, allows you to create an electronic archive); Patentbot (constructs applications for registration of trademarks with the implementation of a preliminary verification of originality); XSUD (systematizes information on court cases and controls the work of employees), etc. These technologies can reduce the time required to carry out standard procedures and create standard contracts and other documents.

There are also technologies in the search for lawyers working in a particular area, taking into account the cost of their services. For example, Legal Space or Platforma (looks for lawyers working on the "no win no fee" model). Such platform helps not only clients, but also lawyers who are looking for partners in different cities.

There are servers for consulting mass clients, for example: Pravoved.ru. Narrowly specific servers are aimed at finding and providing information in any particular area: Glavbukh.ru (the server is not legal, but contains a large number of standards, Huge media companies, such as Action-Mcfr (with 98 magazines, 19 reference systems, 10 services and 21 educational products), offering products such as Sistema Jurist, Corporate Lawyer, etc.

Another interesting direction in the development of LegalTech is analytical systems using artificial intelligence. For example, in Kazan, the Casebook service was created, which allows you to calculate the probability of the outcome and duration of a particular case. [3]. Another example is the joint project of Sberbank and Pravo.ru - Bankro.Tech, which has been active since spring 2018 and is designed to facilitate the work on bankruptcy cases.

Requirements for a modern lawyer are in the digital age.

In the Information Society Development Strategy in the Russian Federation for 2017-2030, a digital economy is defined as an economic activity in which the key factor in production is digital data. Processing large volumes and using the results of analyzing them in comparison with traditional forms of management can significantly improve the efficiency of various types of production, technology, equipment, storage, sale, delivery of goods and services.

Based on the above definition, in the legal sphere work with digital data is the most important component. Therefore, the priority task of lawyers is not only mastering the latest digital technologies, but also using them in their work. 
Today, special services are being created for lawyers that allow you to search, link, categorize, filter and track the legal information they need in their work. Legal Tech in this segment is usually called management or timeline based software, and the segment itself is called management.

A new generation lawyer is able to understand the main categories of the digital economy. In this regard, in the educational process it is necessary to form with future lawyers an objective understanding of cryptocurrencies and the blockchain concept, advantages, disadvantages and risks associated with their use [4, p. 15].

According to experts, the most important functions of a lawyer include analysis, prediction of the situation and the search for optimal solutions. And they can also be automated with the help of artificial intelligence technologies, which will allow you to predict the scenarios and outcome of each specific case, prepare a legal opinion or quickly find the necessary information [6, p. 21]. So, for example, obtaining students digital competencies in the field of forensics is important for the successful investigation of crimes [5].

First of all, digitalization will affect routine operations, such as the selection of judicial practice and the search for the necessary regulations. These functions will most likely be robotized. Thus, junior lawyers will have to retrain as legal analysts, whose task will be a smart search for information using the latest tools. But making a decision based on the selection of information using digital technologies will still remain at the lawyer.

According to experts, similarly, in judicial practice, judicial analysts who can quickly navigate the latest expert-analytical systems will be required. The computer "vision" will be able to accurately determine the emotions of the defendant, the witnesses, and thus will facilitate the work of the jury and prevent pressure attempts, as well as collusion. Forensic examination is also being transformed: since it will be necessary to verify information obtained from digital sources, judicial information experts will appear who are obliged to verify the authenticity of the sources used by the "adviser with artificial intelligence [6, p. 25].

In the era of law digitalization, lawyers have the opportunity to unleash their creative potential through the creation of LegalTech products. At the recently-held LegalTech hackathon in Russia, lawyers presented a number of interesting ideas for automating their activities. Some lawyers are planning or are already learning programming languages, data science and other topics from the field of information technology [6].

It should be noted that the majority of both law students and practicing lawyers are essentially humanities scholars. Nevertheless, the mass introduction of digital technologies in almost all spheres of society's life implies that they must be mastered by lawyers.

Currently, almost all students belong to the generation of digital natives; they demonstrate a much greater propensity to use new technologies in their daily lives. Especially it concerns IT and Internet technologies, as well as their application not only in the professional sphere, but also for socialization and communication.

That is why the development of digital technologies in jurisprudence should be carried out already at the stage of obtaining legal education. At the moment, users are provided with various Internet services. Companies are gradually moving to cloud technologies, distributed business management, data processing and decisionmaking systems. Thus, law students should, in the process of studying at a university, simultaneously with the main educational program, master those digital skills that in the future will help them to effectively perform the function of legal support and integrate the results of work into the company's overall activity.

According to Artem Yudkin, Chairman of the Board of the Siberian Expertise Center Modernization Foundation, legal education should provide a transition from authoritarian and textual didactics (when the future lawyer learns the text of a normative act recommended by the teacher and doctrinal interpretations of legal norms) to a comprehensive perception of information.

The lawyer of the new generation should have the ability to analyze large data files, to build them into logical structures. Already today, in the course of professional activities, a lawyer needs skills to provide services using high-tech tools, such as electronic signatures, electronic document management, cryptochannels for information exchange, tokens and electronic currencies, smart contracts. He must learn to navigate in emerging digital environments: in new software, analytical technologies and reporting platforms that employers or customers use.

Technologies are used in the training of lawyers

Today, education is becoming more technological. At lectures and seminars, teachers must use computer technology with all sorts of presentations, videos, cases, etc. With the advent of smartphones and tablets, it is much more convenient to use a variety of reference and legal search systems when solving situational problems. In preparing for classes, students are encouraged to use materials placed in electronic libraries, legal reference systems and search engines, as well as resources such as document designers.

On July 28, 2017, the Decree of the Government of the Russian Federation No. 1632-p approved the Digital Economy in the Russian Federation program (currently invalid) in which it was planned to adopt law training programs by the end of the first half of 2019 digital economy [7].

The federal project "Personnel for the digital economy" is aimed at achieving the goal defined by Decree of the President of the Russian Federation of May 7, 2018 N 204 regarding solving the task of ensuring the training of highly qualified personnel for the digital economy. This meets the goals and objectives of the Information Society Development Strategy in the Russia Federation for 2017-2030 ", approved by the decree of the President of the Russian Federation of May

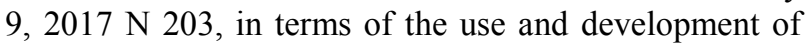
various educational technologies, including remote, electronic learning with the implementation of educational programs. 
Is Russia currently ready to replace traditional educational programs with distant technologies? At the end of 2018, the leadership of the Higher School of Economics announced that in the very near future they plan to abandon traditional lectures and switch completely to video lectures, arguing that neither the students nor the teachers will have to sit in the classroom, and that the audience will increase from 30 to 300 people. This proposal provoked discussion among lawyers and university professors. Our attitude to this is not unambiguous, because a law student, in addition to various purely legal skills, should be able to speak and lead a discussion, and with the full transition to online training, it will be virtually impossible to develop this skill.

An important area of application of digital technologies in education is the development of digital libraries and digital campuses of universities, which have already been introduced by many universities in America, Europe, and Russia.

The questions now facing universities are reduced to the choice of a strategy for further development and the choice of the direction on which it is planned to focus. Obviously, a digital transformation program should be developed now for the transition to a future competitive educational and research model.

Currently, special courses are being introduced in universities aimed at teaching new technologies used in jurisprudence. For example, the Law Faculty of the National Research University Higher School of Economics, together with the law firm Harbor Capital, created the course Lawyer in the Digital Economy. This is the so-called weekend-course for lawyers on the trendiest practical issues in the field of digital law, in particular, on LegalTech, the results of which give participants a certificate of advanced training. As part of a two-day workshop for 8 hours, practicing lawyers learn to work with cryptocurrency, accompany ICO-projects and automate legal processes without interruption from work. Thanks to this course, lawyers get important information about what strategies apply top blockchainprojects, how to reduce risks in an emerging legal environment, how to speed up the work of a law firm or department using artificial intelligence.

The Russian State University of Justice (RSUE) also changed curricula. In particular, such disciplines as legal informatics, information technologies in legal activity, information security have been strengthened. For example, for training specialists on the basis of secondary vocational education to work in the courts, a new specialty has appeared - law and judicial administration. For students enrolled in it one of the most important areas was the study of modern electronic information technologies for working in the courts.

The experience of the Russian Economic University named after G.V. Plekhanov, who, together with the ITTechnology and Efficient Business Resources companies, is implementing an additional education program entitled Legal Basis and Legal Practices for Working with Cryptocurrency and Blockchain Projects. The program is aimed at training lawyers to work with various aspects of the blockchain, cryptocurrency and
ICO, and its goal is to improve the skills of specialists in the field of legal support for the introduction of blockchain technology, smart contracts, various aspects of cryptocurrency functioning, cryptocurrency exchanges, and ICOs in Russia and other countries.

Problems of introducing digitalization in the education process of lawyers.

In order to meet the new requirements, the university must restructure itself: review the approach to the selection and training of scientific and pedagogical staff, develop and license new educational programs. It is required to make students as varied as possible so that they have the opportunity to receive additional education in areas of training related to jurisprudence, such as psychology, linguistics, economics or IT.

At the same time, special attention should be paid to preserving the basic elements of obtaining a classical legal education. It is necessary to find some kind of balance between the continuation of the use of traditional forms and methods of training future lawyers and the mandatory use of current interactive means of communication in the preparation and submission of both educational and methodological material.

It should be noted that in the field of mastering by teachers of higher educational institutions of the latest information technologies and their introduction into the educational process today there are a number of difficulties. A significant part of teachers and managers does not take the initiative, does not update the competence. This happens often in connection with the formality and underfunding of advanced training programs, with a weak practical focus on the training of young teachers. At the same time, it is obvious that the effectiveness of any project in the field of education depends on the motivation and competences of those who train or organize educational activities.

Another problem that should be identified is the financial support of universities for the introduction of digital technologies in the educational process. Computerization, new equipment and technologies - all this requires financial support, which involves the allocation of additional budget funds to universities. As noted in the literature, "At the moment, the amount of financing doesn't meet the requirements of the highquality specialists" [8, p. 224]. A way out of this situation can also be to attract grant money from both private organizations and public structures, for example, regional authorities to involve students in information projects in the region (for example, Monitoring the implementation of projects in public administration $[9, \mathrm{p}$. 81]).

Another serious problem in the preparation of future lawyers is the separation of the theory and practice of higher educational institutions from the specifics of future lawyers' jobs: the court, the prosecutor's office, the internal affairs bodies, the investigating authorities, etc. This problem is due, among other things, to the secrecy of individual programs and databases used in these bodies and institutions. In such a situation, the best solution could be the participation of potential employers in providing the educational process with demonstration, training and testing professional programs. 
For a successful solution of the problems discussed above, a whole range of measures is needed in the development of the legal education system. First of all, we are talking about the retraining of personnel in order to master new educational technologies used in the training of law students.

Equally important is the training of teachers in the application of digital technology in jurisprudence. This is due to the need to continuously improve the forms and methods of teaching, including the teaching of legal disciplines. This direction is successfully implemented in the Volgograd Institute of Management - a branch of RANEPA. Since 2016, an additional professional advanced training program "The Use of Information and Communication Technologies in the Educational Process of Higher Education" has been implemented at the Institute.

In the curriculum of universities, it is necessary to include disciplines that allow the student to acquire skills in the field of new technologies, including the extraction of evidence in the network, cybersecurity, electronic records management and others.

To implement the concept of the digital economy, appropriately trained personnel are needed. First of all, they are specialists in the field of information protection, both from the legal and technical aspects. In the course of teaching such disciplines as civil, financial, information, labor, administrative law, social welfare law, economics and other teachers, it is necessary to pay special attention to the processes and issues related to the digital economy during classes with students. Teachers must form a system of ideas about the digital economy, so that future lawyers can not only thoroughly know the concept of the digital economy, but also successfully implement it in the conditions of modern reality.

In addition to training in universities concerning standard forms of education, today there is a huge number of information products that allow you to independently study and improve. Online training actively developing various advanced training courses are being promoted [10].

Thus, most of the universities offer participation in various programs and schools. Moscow State University offers 7 advanced training programs for lawyers, including: "Countering Extremism", "Mediation", and others. Institute for Advanced Studies University O.E. Kutafina conducts such programs as: "LegalTech Director", designed for 120 academic hours, and aimed at training practicing lawyers who provide guidance on the implementation of the project innovation; "The right of the digital economy: blockchain and smart contracts"; "Legal support of international business".

In addition to universities, a variety of information products aimed at improving the quality of the work of lawyers are offered by various organizations. For example, Garant and Consultant Plus hold various conferences, online round tables, Action-Mcfr media company offers short online courses developed in the info-style system, very informative and easy for citizens to understand.

It offers various schools for the training of specialists and the Skolkovo Technopark, for example, for lawyers in the field of intellectual property rights, on November 1-2, 2018, the Patent School was held.

In various Internet resources one can find lectures of leading scientists and specialists in various branches of jurisprudence. So on YouTube you can see the lectures of Bevzenko R.G., Ivanov A.A., Karapetova A.G. et al.

On Zakon.ru and other similar resources, you can get acquainted with the blogs of scholars and practicing lawyers, find out their point of view about conflicts arising in the law, as well as about the limits of application of legal norms, etc. In addition, this resource contains many analytical articles.

Today, the teaching of legal disciplines is developing in two aspects: traditional and innovative [11].

It seems that a modern teacher should not only use the existing opportunities for today, but also acquaint students with them, teach them to use various resources and technologies. And all this is possible to do both in the mode of live communication, and with independent preparation of students. For example, in the lectures illustrating the theoretical part with examples, you can use various resources. For example, when studying the procedure for registering legal entities, acquaint students with the ability to quickly fill in various applications by using online fill-in designers. As part of the study of patent law, talk about the possibilities of applying patent search technologies, searching forms and documents on the Rospatent website. On couples in a civil and arbitration process, students should be told about the possibility of filing documents in electronic form, as well as the possibility of using the state fee calculator.

\section{Conclusion}

The main task of the modern university, which prepares future lawyers, is the combination of humanitarian and technical knowledge and skills, as well as the development of students' skills in working with modern technical means.

Training of future lawyers must wear the systemic nature of the application. Graduates of law schools should be able to confidently qualify a specific legal situation, receiving the necessary information from a variety of sources, including electronic ones, which implies a high level of mastering the skills of using digital technologies. A 21st-century lawyer needs to know the basics of electronic document circulation, to be able to create electronic documents (claims and other applications, complaints, various requests), that is, to interact with various individuals and legal entities through information and telecommunication technologies. At the same time, legal and technical protection against the distortion of information must be taken into account. For example, the introduction of big data in everyday legal practice should significantly reduce the significance of the examination of documents. Using these systems, backdating of illegal information will be increasingly difficult. This, of course, will simplify the work of a lawyer, because less will have to deal with dishonesty opponents. 
In today's world there are many technologies aimed at simplifying the work of a lawyer and reducing time costs. It seems that future lawyers need to be trained in the classic sense and taught how to use various technical means. In addition, the use of various technical means will allow more complete disclosure of information on the topics studied, as well as help to make the classes more practical.

This scientific work was supported by Volgograd Institute of Management - the branch of RANEPA, as part of the execution of scientific project No. 04-2018VIM "Actual problems of the protection of rights and freedoms in the digital space".

\section{References}

1. D. Mungalov Law \& Code: about the problems of automation of law. Retrieved from: https://vskgitlab.sk.ru/news/b/articles/archive/2017/12/01/law_ 2600 code-o-problemah-avtomatizacii-prava.aspx (2017).

2. A. Pelevin Russia - in the top countries in terms of the development of LegalTech. Retrieved from: https://rb.ru/opinion/legaltech-interview/ (2017).

3. O. Lugovoy In Kazan, they began to create a lawyer robot capable of predicting the decision of a KP judge Retrieved from: https:/www.kazan.kp.ru/daily/26599/3615075/ (2019).
4. M. Moiseev Decentralized cryptocurrencies and blockchain technology in the context of the educational process. Proc. of the Int. sc. meth. conf. (2018).

5. Yu. Krasnenko The use of digital technologies in criminalistic training of subjects of crime investigation. MTDE (2019).

6. Legaltech and lawyers of the future. Law. 11. 20-36. Retrieved from: https://www.simplawyer.com/wpcontent/uploads/Zakon.ru-Legal-Tech-and-lawyersof-the-future.pdf (2017)

7. N. Khramtsova, T. Mayboroda Approaches to the development of digital competencies of law students. Per. Sc. Ed. 37 (1), 80-93. (2019)

8. Y. Pereverzeva, A. Shamne Financing higher education: experience of Russia and Germany. CILDIAH (2017).

9. M. Tsurkan, S. Mironova, N. Pilipchuk Digital transformation of project implementation monitoring in the regional public management. CILDIAH (2017).

10. S. Palvia Online Education: Worldwide Status, Challenges, Trends, and Implications J. Gl. Inf. Tech. Man., 21:4, 233-241 (2018).

11. E. Khovanskaya, S. Vasyukov, Z. Ibragimova Use of digital technologies in teaching legal disciplines. MTDE (2019). 